\title{
GLOSSOPTERIDDEAS DE FLUVIÓPOLIS (PERMIANO SUPERIOR) NO SUL DO ESTADO DO PARANÁ
}

\author{
J.A.J. PERINOTTO \\ O. RÖSLER ${ }^{2}$
}

\begin{abstract}
This paper describes the Glossopteris species of a compact carbonaceous siltstone of the Upper Permian Serra Alta (or Terezina?) Formation (Parana Basin), cropping out along the right margin of the Iguaçu River, néar Fluviópolis, State of Paraná, southern Brazil. The study of over 100 specimens related to the genus Glossopteris showed that they predominantly are of two possibly new species. However, because the small number of specimens with well preserved venation does not constitute an adequate basis for the creation of new species, the specimens are here referred to Glossopteris cf. G. occidentalis and Glossopteris cf. G. angustifolia.
\end{abstract}

\section{RESUMO}

O presente trabalho descreveve as glossopterídeas procedentes de um afloramento de siltitos calcíferos compactos, provavelmente pertencentes à Formação Serra Alta, e situado à margem direita do Rio Iguaçu, próximo a Fluviópolis, no Estado do Paraná. Foram coletadas mais de 100 amostras de glossopterídeas que aparecem como finas películas carbonosas, já sem estrutura ou preservaçåo de cutícula. Após a retirada das películas, observam-se impressões com qualidade variável.

São descritas duas formas: uma apresentando uma nervura mediana bastante larga, estriada longitudinalmente e bem marcada. As nervuras secundárias emergem em ângulo bastante agudo, sofrem dicotomias e anastomoses próximo da nervura mediana e se encurvam abruptamente alcançanda a margem em ângulos de cerca de $80^{\circ}$. Apresentam maior semelhança com G. occidentalis da qual diferem, sobretudo, por apresentarem tamanho médio bem menor dos espécimes. Um segundo grupo de formas, representado principalmente pela porção médio-apical do limbo foliar, foi determinado como Glossopteris cf. G, angustifolia.

\section{INTRODUCุÃO}

Neste trabalho descrevem-se as glossopte. rídeas da localidade de Fluviópolis, no sul do Estado do Paraná, coletadas por um dos autores (O.R.) em 1974.

No local (AF/GP 86, RÖSLER, 1982:12 e 18), uma antiga pedreira situada d margem do Rio Iguaçu, além dos mais de cem exemplares coletados de glossopterídeas ocorrem outras formas como Paracalamites australis e ? Lycopodiopsis sp (vide OLIVEIRA-BABINSKI \& RÖSLER, neste volume).

As formas de glossopterídeas sđ̃o diversificadas, relativamente bem conservadas quanto à visualização de sua forma e aspectos gerais, porém apresentando alguma dificuldade no re. conhecimento de detalhes da nervação. Não haviam ainda sido descritas, muito embora se constituam em elementos muito importantes

\footnotetext{
${ }^{1}$ UNESP-Rio Claro e Pós-graduando do IG-USP.

${ }^{2}$ Instituto de Geociências, Universidade de Săo Paulo.
}

para o esquema bioestratigráfico da Bacia do Paraná.

Em termos da posição na coluna litoestratigrafica, em que pese o isolamento do afloramento, a litologia onde se encontram impressos os espécimes (siltitos cinza, calcíferos e compactos) remete à Formação Serra Alta, embora ñ̃o se possa descartar a possibilidade de tratarse da Formaçăo Terezina, proposta pela Mineropar-Minerais do Paraná, em seu mapa 1:500.000 (inédito).

As formas descritas aparecem como finas películas carbonosas, que após tratamento não apresentam estrutura ou preservação de cutícu. la. Com a retirada da película, observam-se impressøes com qualidade variável. Nenhum dos exemplares apresenta-se inteiro, estando a maioria preservada em sua parte mediana e/ou médio-apical.

Os métodos utilizados na análise foram de observaçăo direta através de lupa binocular e exame de fotografias de alto contraste.

$\mathrm{O}$ material encontra-se depositado na $\mathrm{Co}$. 
leçå de Paleobotânica do Departamento de Paleontologia e Estratigrafia do IG-USP.

\section{SISTEMATICA}

Gênero Glossopteris Brongniart, 1828

Glossopteris ef. G. occidentalis WHITE, 1908

Figs. 1 e 2; Estampa 1, figs. 1 a 3; Tabela 1

Descriçāo: Os exemplares estão representados pela porção média das folhas. Nenhum deles mostra as terminaçōes basal ou apical, dificultando a caracterizaçăo a nível específico.

Alguns parâmetros morfológicos observados podem ser sumariados conforme a Tabela 1 .

$\begin{array}{ccccc}\begin{array}{c}\text { Exemplar } \\ \text { GP/3T }\end{array} & \begin{array}{c}\text { Comprimento } \\ \text { minimo } \\ (\mathrm{mm})\end{array} & \begin{array}{c}\text { Largura Largura } \\ \text { maxima minima } \\ (\mathrm{mm})\end{array} & \begin{array}{c}\text { Largura } \\ \text { (mm) }\end{array} & \begin{array}{c}\text { vara mer- } \\ \text { diana } \\ \text { (mm) }\end{array} \\ 1456 & 86 & 27 & 19 & \begin{array}{c}8 \text { (prox.) } \\ \text { (dist.) }\end{array} \\ 1457 \text { a } & 61 & 22 & 22 & 7 \\ 1458 & 47 & 22 & 22 & 6 \\ 1459 \text { a } & 43 & 21 & 21 & 6 \\ 1460 \text { a } & 50 & 27 & 27 & 6\end{array}$

Tabela 1 - Comprimentos e larguras dos limbos foliares o larguras das nervuras medianas em cinco espécimes de Glossopteris cf. G. occidentalis de Fluviópolis, PR.

Os bordos sđ̃o aproximadamente paralelos nas porçбes medianas sendo que no exemplar GP/3T 1456 nota-se a diminuiçđo da largura do limbo para a base (Fig. 1). Sugerem uma forma retilínea tendendo a lanceolada.

A nervura mediana é característicamente bem marcada, estriada longitudinalmente e larga com estreitamento para o ápice (Figs. 1 e 2).

A nervação secundária emerge em ângulo bastante agudo e logo após sofrer dicotomias e anastomoses irregulares, encurva-se abruptamente adquirindo um ângulo de $80^{\circ}$ a $90^{\circ} \mathrm{em}$ relaçđ̃o à nervura mediana, mantendo-se assim até atingir o bordo da folha. Uma exceção é o exemplar GP/3T 1460a que apresenta, próximo à margem, uma leve inflexăo da nervação para cima. As dicotomias e anastomoses são relativamente mais abundantes próximo à nervura mediana, dando um reticulado com malhas mais amplas. Após a inflexão para ângulos quase retos, a nervação torna-se densa, com reticulado de malhas longas e finas e com dicotomias e anastomoses mais raras e de difícil visualização. 0 número estimado de nervuras por centímetro próximo à margem é da ordem de $40 \mathrm{a} 45$.
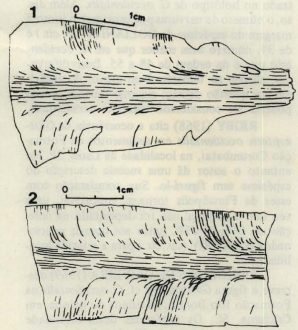

Figs, 1, 2 - Esquemas de Glossopteris cf. G. occidentalis mostrando a forma e caracter isticas da nervaçăo (Fig. 1 - Especime GP/3T-1456; Fig. 2 - Especime GP/3T-1459A).

Discussão: Dentre as espécimes de Glossopteris descritas para a Bacia do Paraná, os espécimes ora descritos de Fluviópolis se aproximam mais de Glossopteris occidentalis WHI. TE (1908: 510-516, est. VII, fig. 1 a 4 a), descrita com base em material procedente da Formaçāo Rio Bonito, região de Lauro Müller, SC. Referências posteriores sobre essa espécie aparecem no trabalho de OLIVEIRA (1927), no qual o autor apenas cita a ocorrência de $G$. occidentalis em sedimentos do Grupo Tubarđo em um "grotão a oeste de Teixeira Soares" (OLI. VERIA, 1927, p. 72), no Estado do Paraná. O espécime referido nåo foi descrito nem figurado e tampouco faz-se mençăo de onde se encontra depositado, tornando impossivel uma comparação. Os espécimes descritos por READ (1941: 76-77, 78-79, est. 4, figs. 3 e 5) como Glossopteris $\mathrm{cf}$. G. ampla apresentam características que muito os aproximam de G. occidentalis a des. peito daqueles apresentarem-se com dimensōes bem maiores que estes, se as escalas indicadas por READ (op. cit.) estiverem corretas. Esta aproximação já foi observada e citada por BER. NARDES-DE-OLIVEIRA (1969). Esta mesma autora relaciona com Glossopteris occidentalis o espécime descrito por DOLIANITI (1953) como Glossopteris stricta BUNBURY. Revendo-se as estampas de DOLIANITI (op. cit.), observa-se que o ângulo de curvatura da nervaf̧ão secundária năo é tăo aberto quanto ao ilus. 
trado no holótipo de $G$, occidentalis. Além disso, o número de nervuras por centímetro junto à margem do espécime de DOLIANITI (op. cit.) é de 39 , número bem menor que em $G$. occidentalis que $e$ da ordem de 48 a 55 . Essas diferenças, aliadas ao tamanho bem menor do espécime em questão deixam algumas dúvidas se esse poderia ser considerado como G. occidentalis.

RIGBY (1968) cita a ocorrência de Glossopteris occidentalis em sedimentos da Formação Corumbataí, na localidade de Laras, SP. No entanto o autor dá uma sucinta descriçăo do espécime sem figurá-lo. Sua comparação com esses de Fluviópolis torna-se impossivel, uma vez que o material não foi depositado na coleçăo do DPE-IG-USP, junto aos demais relacionados por RIGBY (op. cit.) para a referida localidade.

BERNARDES-DE-OLIVEIRA (1969) descreve e figura Glossopteris cf. G. occidentalis na Formação Rio Bonito, na subida do Bainha, em Criciuma, SC. Os espécimes desta localidade aproximam-se destes de Fluviópolis por apresentarem densidade de nervaçāo elevada, largura e estriaçбes da nervura mediana, número maior de dicotomias e anastomoses e em malhas mais amplas próximo à nervura mediana. No entanto, os espécimes do Bainha diferem destes de Fluviópolis principalmente por serem mais largos e pelo ângulo de divergência da nervação secundária que assume valores de $65^{\circ}$ a $70^{\circ}$ naqueles e de $80^{\circ}$ a $90^{\circ}$ nestes.

RIGBY (1972) descreve G. occidentalis para o horizonte Joaquim Branco, Formaçăo Rio Bonito, em Lauro Müller, SC, O espécime encontra-se na Coleçăo de Paleobotânica do IG-USP sob número GP/3T 1172 e sua comparaçăo com esses de Fluviópolis mostra algumas semelhanças como a larga e estriada nervura mediana, a densa nervaçđ̃o secundária que emerge com ângulo bastante agudo e abruptamente adquire valores de quase $90^{\circ}$. No entanto, o espécime de Lauro Muller é sensivelmente mais largo que os presentemente descritos, fato que o aproxima mais da descrição do holótipo da espécie.

Para os exemplares de Fluviópolis, as características como nervura mediana larga e estriada, ângulo bastante agudo de divergência da nervaçăo secundária, que abruptamente assume valores de $80^{\circ}$ a $90^{\circ}$, número maior de dicotomias e anastomoses com malha mais larga próximo à nervura mediana, nervação densa com reticulado longo e fino após a inflexāo para ângulos quase retos, levam a interpretá-los como mais próximos de Glossopteris occidentalis.

Em que pese a falta das partes basais nos exemplares ora descritos, a tendência em năo apresentar a base cordiforme postulada por WHITE (1908) na diagnose da espécie, parece ser mais uma regra que uma exceçăo, conforme se observa também na maioria das descriçóes dos autores já anteriormente citados. Aliás, observando-se a figura 2 da Est. VII de WHITE (op. cit.) fica-se em dúvida se se trata realmente de uma terminaçāo cordiforme ou de uma partição da amostra que conferiu ao exemplar figurado essa forma terminal.

A comparação com outras formas já des. critas para o Gondwana mostra que esses espécimes de Fluviópolis apresentam-se com determinadas características que a rigor poder-se-ia dizer de uma espécie nova. No entanto, a falta de maiores detalhes, devido à qualidade da preservação e ao número pequeno de exemplares analisados, ainda nao permite tal afirmação, pelo que prefere-se denominá-los de Glossopteris cf. G. occidentalis.

Material estudado: GP/3T 1456; 1457a; $1458 ; 1459 \mathrm{a} ; 1460 \mathrm{a}$. Material depositado na Coleçāo de Paleobotânica, DPE-IG-USP.

Glossopteris cf. G. angustifolia BRONGNIART, 1830

Fig. 3; Estampa 1, figs. 4 e 5

Descriçāo: Esse segundo grupo de formas em que se apresentam as glossopterideas de Fluviópolis encontra-se preservado, em sua maioria, na porção médio-apical da folha e sugerindo uma forma estreita e linear, tendendo a ter um ápice agudo (Est. 1, fig. 5).

Os exemplares sฐ̃̄o longos, com comprimento mínimo variável, de 56 a $145 \mathrm{~mm}$, porém a largura máxima é bastante regular, da ordem de $23 \mathrm{~mm}$ na parte mais proximal preservada.

A nervura mediana é nítida e persistente por todo o comprimento com estreitamento para o ápice. Onde é mais larga (2 a $3 \mathrm{~mm})$ apresenta-se estriada longitudinalmente (Fig. 3).

As nervuras secundárias tem ângulo de emergência agudo (da ordem de $20^{\circ}$ ) e curvamse atingindo ângulos de $70^{\circ} \mathrm{a} 80^{\circ}$, prosseguindo retas até a margem. A observação do reticulado resultado das dicotomias e anastomoses é difjcultada pelo estado de preservação, porém parece que próximo à nervura mediana as malhas sฐ̃o mais amplas que no restante da folha, onde a densidade de nervação é maior, com as malhas longas e finas e as nervuras quase paralelas. $O$ número de nervuras por centímetro junto à margem é da ordem de 25 .

Discussäo: Essa espécie vem sofrendo ao longo dos anos uma série de observações de muitos pesquisadores que apresentam diferentes 
Paleobotannica Palinologia na Am. do Sul - 1983 - Bol. IG.USP, Inst, de Geociencias, USP, 15: 13-150, 1984

ESTAMPA I

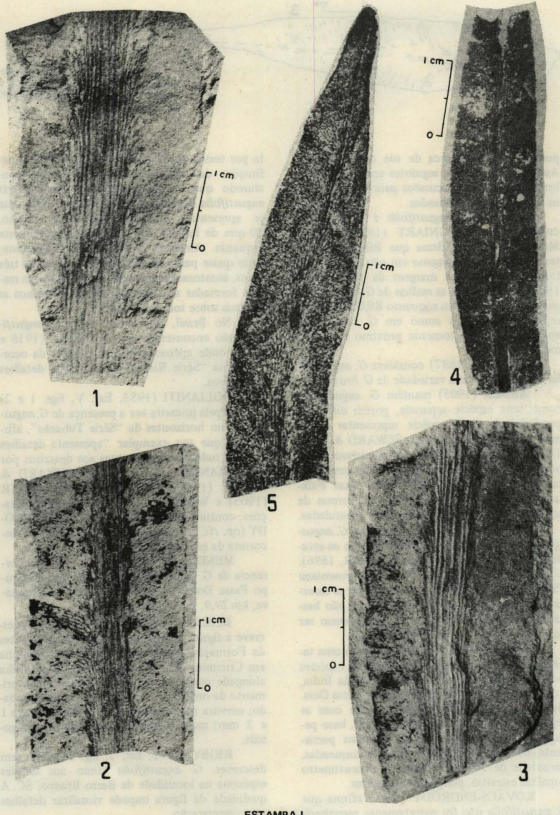

EST AMPA I

Figs, 1 a 3-Glossopteris cf. G, occidentalis (Fig. 1 -Espécime GP/3T-1456; Fig. 2 - Espécime GP/3T- 1459a; Fig. 3 - Especime GP/3T-1458).

Figs, 4,5 - Glossopteris cf. G, angustifolia (Fig, 4 - Espécime GP/3T-1446; Fig. 5 - Espécime GP/3T-1453). 


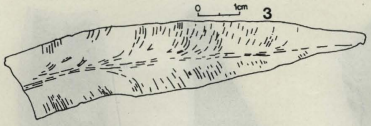

Fig. 3 - Esquema de Glossop. teris cf. $G$, angustifolia mostrando o tracado da nervaçðo (especime GPI 3T. 1453 )

pontos de vista acerca de sua caracterização. Assim, os parágrafos seguintes tentam historiar brevemente essas discussōes para melhor situar os espécimes ora analisados.

Glossopteris angustifolia é uma espécie criada por BRONGNIART (1830). FEIST. MANTEL (1876) afirma que BRONGNIART teria cometido um engano em nđo figurar anas. tomoses próximo à margem da folha e, em 1881 , comenta que as malhas de $G$. angustifolia chegam até a margem enquanto BRONGNIART representa as veias como em $G$. browniana, anastomosando-se somente próximo à nervura mediana.

SEWARD (1897) considera G. angustifolia como sendo uma variedade de G. browniana.

ARBER (1905) mantém G. angustifolia como uma espécie separada, porém discute a possibilidade dessa espécie representar folhas mais estreitas de $G$. indica. SEWARD \& WAL. TON (1923) afirmam que nao existem dados para se separar essas duas espécies, com base nos exemplares colecionados nas Il ihas Falklands, onde os autores observaram formas de transição entre as folhas lineares e espatuladas.

PLUMSTEAD (1952) pensa que $G$. angustifolia é similar a $G$, browniana, porém os estudos cuticulares de $G$. indica (ZEILLER, 1896), G. angustifolia (SAHNI, 1923) e G. browniana (SRIVASTAVA, 1956) mostraram que as características epidérmicas das três espécies são bastante distintas e diferentes e assim devem ser mantidas como espécies independentes.

MAHESHWARI (1964) apresenta uma tabela mostrando as feiçōes salientes das espécies de Glossopteris do Andar Raniganj, da India, que corresponderia ao nosso Grupo Passa Dois. Nesta tabela, $G$, angustifolia aparece com as seguintes características: forma linear, base petiolada, ápice agudo, nervura mediana persistente, nervuras secundárias oblíquas, arqueadas, densidade de 24 a 30 nervuras por centímetro e malhas estreitas, poligonais-elongadas.

KOVẢCS-ENDRÓDY (1981) afirma que G. angustifolia nāo foi corretamente reconhecida por FEISTMANTEL (1876, 1881), ARBER (1905) e SEWARD (1910), e consequentemen- te por todos quantos levaram em conta suas definiçōes da espécie para identificaçōes, concluindo que o nome específico Glossopteris angustifolia Brongniart está restrito a folhas que se apresentam lineares com ápice obtuso, $20 \mathrm{~mm}$ de largura, venaçăo lateral suavemente arqueada atingindo a margem obliquamente; veias quase paralelas bifurcando-se duas ou três vezes, anastomosando-se ocasionalmente; as malhas formadas săo lineares e mais ou menos as mesmas sobre toda a lâmina.

No Brasil, referências sobre $G$. angustifolia sāo encontradas em OLIVEIRA (1918 e 1927) onde apenas aparecem citaçoes da ocorrência na "Série Rio do Rasto", sem detalhes descritivos.

DOLIANITI (1953, Est. V, figs. 1 e 2) assinala pela primeira vez a presença de $G$. angustifolia em horizontes da "Série Tubarão", afir. mando que seu exemplar "apresenta detalhes que em tudo sto semelhantes aos descritos por FEISTMANTEL (1881, 1882), SEWARD \& LESLIE (1908), SEWARD (1910), ARBER (1905) e WALKOM (1928)". Essas comparaçóes, contudo, como afirma KOVẢCS-ENDRÖ. DY (op. cit.) podem levar a uma classificaçāo in. correta da espécie.

MENDES (1954, Est. 1; fig. 3) cita a ocorrência de $G$. angustifolia em horizontes do Grupo Passa Dois, na ferrovia Gutierrez-Guarapuava, $\mathrm{km} 29,9$, porém nqo a descreve.

BERNARDES-DE-OLIVEIRA (1969) descreve a figura $G$. angustifolia para os horizontes da Formaçăo Rio Bonito, na subida do Bainha em Criciuma, SC, afirmando tratar-se de folha alongada com largura de 2 a $2,4 \mathrm{~cm}$ e comprimento da ordem de $10 \mathrm{~cm} . \mathrm{O}$ ápice é arredondado; nervura mediana nftida com largura entre 1 e $2 \mathrm{~mm}$; malhas estreitas, alongadas e poligonais.

RIGBY (1972, Est. 2, fig. 14) cita, sem descrever, $G$. angustifolia como um simples espécime na localidade de Barro Branco, SC. A qualidade da figura impede visualizar detalhes para comparação.

BERNARDES-DE-OLIVEIRA (1977, Est. 12, fig. 2; Est. 14, figs. 1, 3-5; figs,-texto $53 \mathrm{e}$ 
54) descreve para a Camada Irapuá da Forma. çăo Rio Bonito, formas de folha estreita e linear com largura máxima de 10 a $24 \mathrm{~mm}$ e comprimento até $100 \mathrm{~mm}$, nervura mediana estriada longitudinalmente, nítida e persistente com $2 \mathrm{~mm}$ de largura e estreitando-se para o ápice. Nervuras secundárias emergindo com ângulo agudo, curvatura suave a $1 / 3$ do percurso prosseguindo retas até a margem. Reticulado longo e poligonal estreito, mais aberto próximo à nervura mediana com raras anastomoses próximo à margem. A densidade de nervação apresenta 11 a 18 nervuras por centímetro junto à mar. gem.

Os exemplos de Fluviópolis, conforme a descriçăo, apresentam certas feiçōes como a forma linear e estreita com ápice tendendo a agudo; largura máxima de $23 \mathrm{~mm}$; nervura mediana nítida e persistente, estriada longitudinalmente, com largura de 2 a $3 \mathrm{~mm}$, estreitando-se para o ápice; nervação secundária emergindo com ângulo agudo; reticulado com malhas relativamente mais amplas próximo à nervura mediana e malhas longas e estreitas, com as nervuras quase paralelas pelo restante da folha e densidade de nervaçáo da ordem de 25 nervuras por $\mathrm{cm}$ junto à margem, que nāo correspondem exatamente à definiç̧ão da espécie dada por BRONGNLART (1830), porém aproximam-se de $G$. angustifolia sensu MAHESHWARI (1964) e BERNARDES-DE-OLIVEIRA (1969 e 1977).

No entanto, o longo comprimento de alguns exemplares e a curvatura mais acentuada da nervação secundária, que atinge a margem com ângulos de até $80^{\circ}$ em relação à nervura mediana, sđo características que levam os autores a classificar esses exemplares em questão como Glossopteris of. G. angustifolia.

Material estudado: GP/3T 1444a, b; $1445 \mathrm{a} ; 1446 ; 1447 ; 1448 ; 1450 ; 1451 ; 1452 \mathrm{a}$; 1453b; 1454 (Coleção de Paleobotânica do DPE-IG-USP).

\section{CONSIDERACุÕES FINAIS}

Embora dispondo de mais de uma cente. na de exemplares de glossopterídeas de Fluviópolis, grande parte delas mostrando a forma e aspectos grosseiros da nervação, que permitem reconhecer o gênero Glossopteris, apenas 16 espécimes apresentam detalhes de nervação suficientes para consideraçбos ao nível específico.

De acordo com as descriçōes e discussōes apresentadas neste trabalho, verifica-se que se tratam de formas relativamente distintas de todas as espécies já descritas para o gênero. $\mathrm{O}$ conjunto de diferenças chega a sugerir pelo menos duas novas espécies. Contudo, considerando-se o número limitado de amostras com detalhes bem conservados, preferiu-se, de momento, designá-las de acordo com as espécies morfograficamente mais próximas: Glossopteris of. G. occidentalis e Glossopteris cf. G. angustifolia. Outras formas distintas destas estão também presentes na coleçåo. Algumas delas apresentam forma extremamente alongada, com cerca de $120 \mathrm{~mm}$ de comprimento preservado, podendo atingir mais de $200 \mathrm{~mm}$, nervura mediana nítida e persistente e nervaçå secundária com malhas distintas.

Pela discussão aqui apresentada com relação a $G$. angustifolia, evidencia-se também a necessidade de uma revisāo crítica desta espécie, cuja caracterizaçáo, através de parâmetros morfográficos, encontra-se um tanto confusa na literatura.

A ocorrência de glossopterídeas nesta nova localidade fossilífera no sul do Estado do Paraná fica portanto pela primeira vez registrada. Convém chamar a atençåo para a importância desse tipo de estudo, tendo em vista que a grande maioria dos trabalhos anteriores referem-se a ocorrências no Grupo Tubarđo, o que constituia, e de certa forma constitui ainda, um entrave para a efetiva aplicação bioestratigráfica das glossopterídeas. Seria ideal que densidade de informaçóes sobre as mesmas no Grupo Passa Dois fosse aumentada através de estudos semethantes, em outras localidades.

\section{BIBLIOGRAFLA}

ARBER, E.A.N. - 1965 - Catalogue of the fossil plants of the Glossopteris Flora in the Department of Geology. British Museum (Natural History), London.

BERNARDES-DE-OLIVEIRA, M.E.C. - 1969 - Flora da Formaçđ̄o Rio Bonito: Glossopteris, Noeggeratiopsis, Sphenopteris, Gangamopteris $e$ Rhabdotaenia, na subida do Bainha, Criciuma, SC. Dissertaçāo de Mestrado apresentada ao IG/USP.

BERNARDES-DE-OLIVEIRA, M.E.C. - 1977 - Tafoflora Eogondvânica da Camada Irapud, Formaçūo Rio Bonito (Grupo Tubarüo), S.C. Tese de doutoramento apresentada ao Inst. Geociências, USP, 2 vols., 301 p., 36 estampas, 124 figuras no texto. 
BRONGNIART, A. - 1830 - Histoire des végetaux fossiles. Paris.

DOLIANITI, E. - 1953 - A flora do Gondwana inferior em Santa Catarina, DNPM/DGM. Notas Preliminares e Estudos, 60:1-7.

FEISTMANTEL, O. - 1876 - On some fossil plants from Damuda Series in the Raniganj Coalfield, collection by Mr. J. Wood-Mason. Journal Asiat. Soc. Beng., 45 : 329-382.

FEISTMANTEL, O. - 1881 - The fossil flora of the Gondwana System. The flora of the Damuda.Panchet divsions. Rec. Geol. Surv. India. Palaentographica Indica Ser. XII, 3(3) : 78-149.

FEISTMANTEL, O, - 1882 - Fossil Flora of Gondwana System. Pal. Indica, IV(1): 1-52.

KOVACS-ENDRÖDY, E. - 1981 - Notes on Glossopteris angustifolia Brongniart. The Palaeobotanist, 28/29: 53-62.

MAHESHWARI, H. K. - 1964 - Studies in the Glossopteris Flora of India. 22 - On some species of the genus Glossopteris from Raniganj Stage of the Ranignaj Coalfield, Bengal. The Palaeobotanist, 13(2): 129-143.

MENDES, J.C. - 1954 - Contribuiģâo à estratigrafia da série Passa Dois no Estado do Parand. USP - FFCL, Bol. 175 , Geologia (10): 1-119, 3 est.

MINEROPAR - Minerais do Paraná S/A - Mapa Geológico do Paraná na escala - 1500.000 (inédito).

OLIVEIRA, E.P., in HOLDHAUS, K. - 1918 - Anexo a: Sobre alguns lamelibránquios fósseis do sul do Brasil. Mon. Div, Geol. Bras,, 2:27-32.

OLIVEIRA, E. P. - 1927 - Geologia e recursos minerais do Estado do Parand. Mon. Div. Geol. Mineral. Bras., 6 : $1-172$.

PLUMSTEAD, E. P. - 1952 - Description of two new genera and six new species of fructifications borne on Glossopteris leaves. Trans. Geol. Soc. S. Afr., $55: 281-328$.

READ, C. B. - 1941 - Plantas fósseis do Neo-Paleozóico do Parand e Santa Catarina. Mon. Div. Geol. Mineral. Bras., $12: 1-102$.

RIGBY, J. F. - 1968 - New fossil plant locality near Laras, State of Sāo Paulo. Anais do XXII Congresso Brasileiro de Geologia (1968) : 201-208

RIGBY, J. F. - 1972 - The Upper Palaeozoic flora at Lauro Maller, Santa Catarina, Southern Brazil. Simpósio Internacional sobre os Sistemas Carbonffero e Permiano da América do Sul, Anais da Academia Brasileira de Ciencias, 44, suplemento : $279-293$.

ROSLER, O. - 1982 - Coleçoes de megafósseis vegetais do Instituto de Geociéncias (Departamento de Paleontologia e Estratigrafia), Universidade de Sđo Paulo. Bol. Associaç̃o Latinoamer. Paleobot. Palinol, 8 (1981) : 1-20, Buenos Aires.

SAHNI, B. - 1923 - On the strucrure of the cuticle on Glossopteris angustifolia Brong. Rec. Geol. Surv. India, 54 (3) : $277-280$.

SEWARD, A. C. - 1910 - Fossil Plants. II. Cambridge Univ. Press.

SEWARD, A. C. \& LESLIE, T. N. - 1908 - Permo-Carboniferous plants from Vereeniging, Quart. Journ. Geol. Soc. London, $44: 109-126$.

SEWARD, A. C. \& WALTON, J. - 1923 - On fossil plants from the Falklands Islands. Quart. Journ. Geol. Socl. London, $79: 313-333$

SRIVASTAVA, P. N. - 1956 - Studies in the Glossopteris Flora of India, IV Glossopteris, Gangamopteris and Palaeovittaria from the Raniganj Coalfield. The Palaeobotanist, $5(1): 1-45$.

WALKOM, A. B. - 1928 - Notes on some additions to the Glossopteris flora in New South Wales. Proc. Linn. Soc. N. S, Wales, 53(III).

WHITE, D., in WHITE, I, C. - 1908 - Flora fossil das "coal measures" do Brasil - Relatório Final da Comissīo de Estudos das Minas de Carvão da Pedra do Brasil. Parte III : $337-617$.

ZEILLER, R, - 1896 - Etude sur quelques plantes fossiles, en particulier Vertebraria et Glossopteris, des environs de Joannesburg (Transwaal), Bull, Soc, Géol, Fr., 24(3) ; 349-378. 